\title{
Brief Electrical Stimulation Promotes the Speed and Accuracy of Motor Axonal Regeneration
}

\author{
Abdulhakeem A. Al-Majed, ${ }^{1}$ Catherine M. Neumann, ${ }^{1}$ Thomas M. Brushart, ${ }^{2}$ and Tessa Gordon ${ }^{1}$ \\ ${ }^{1}$ Department of Pharmacology, Division of Neuroscience, University of Alberta, Edmonton, Alberta T6G 2S2, Canada, \\ and 'Departments of Orthopedic Surgery and Neurology, Johns Hopkins Medical School, Baltimore, Maryland
}

Functional recovery is often poor despite the capacity for axonal regeneration in the peripheral nervous system and advances in microsurgical technique. Regeneration of axons in mixed nerve into inappropriate pathways is a major contributing factor to this failure. In this study, we use the rat femoral nerve model of transection and surgical repair to evaluate (1) the effect of nerve transection on the speed of regeneration and the generation of motor-sensory specificity, (2) the efficacy of electrical stimulation in accelerating axonal regeneration and promoting the reinnervation of appropriate muscle pathways by femoral motor nerves, and (3) the mechanism of action of electrical stimulation. Using the retrograde neurotracers fluorogold and fluororuby to backlabel motoneurons that regenerate axons into muscle and cutaneous pathways, we found the following. (1) There is a very protracted period (10 weeks) of axonal outgrowth that adds substantially to the delay in axonal regeneration (staggered regeneration). This process of staggered regeneration is associated with preferential motor reinnervation (PMR). (2) One hour to 2 weeks of $20 \mathrm{~Hz}$ continuous electrical stimulation of the parent axons proximal to the repair site dramatically reduces this period (to 3 weeks) and accelerates PMR. (3) The positive effect of short-term electrical stimulation is mediated via the cell body, implicating an enhanced growth program. The effectiveness of such a short-period lowfrequency electrical stimulation suggests a new therapeutic approach to accelerate nerve regeneration after injury and, in turn, improve functional recovery.

Key words: electrical stimulation; staggered regeneration; motoneuron; TTX; PMR; retrograde labeling
Injured mammalian peripheral nerves can regenerate over long distances (for review, see Fu and Gordon, 1997). However, it is a common clinical experience that functional recovery does not ensue unless transected nerves are surgically repaired to guide regenerating axons into the growth environment of the distal nerve stump (Sunderland, 1978; Kline and Hudson, 1995). Even then, surgical repair often fails to achieve significant functional recovery, particularly if the injury requires regeneration over long distances and, thus, months and even years of regeneration (Sunderland, 1978; Kline and Hudson, 1995). These periods are much longer than predicted from reported regeneration rates of 1-3 $\mathrm{mm} / \mathrm{d}$ and the latent period of 3-7 $\mathrm{d}$ for axons to regenerate across the surgical site and form functional connections (Gutmann et al., 1942; Sunderland, 1947, 1978; Kline and Hudson, 1995).

Axonal regeneration from the proximal stump into inappropriate distal pathways after nerve transection has been long recognized as a factor contributing to poor functional recovery (Langley and Hashimoto, 1917; Sunderland, 1978; Kline and Hudson, 1995). For example, when regenerating motor axons enter Schwann cell tubes in the distal stump that lead to sensory nerve

\footnotetext{
Received Nov. 29, 1999; revised Jan. 21, 2000; accepted Jan. 26, 2000.

This work was supported by the Medical Research Council of Canada. A.A.A.-M. is supported by The Royal Embassy of Saudi Arabia. It partially fulfills the requirements for the PhD and MSc theses for A.A.A.-M. and C.M.N., respectively. T.G. is an Alberta Heritage Foundation for Medical Research senior scientist.

Correspondence should be addressed to Dr. Tessa Gordon, Department of Pharmacology, Division of Neuroscience, 513 Heritage Medical Research Center, University of Alberta, Edmonton, Alberta T6G 2S2, Canada. E-mail: tessa.gordon@ ualberta.ca.

Copyright (C) 2000 Society for Neuroscience $\quad 0270-6474 / 00 / 202602-07 \$ 15.00 / 0$
}

branches, they are directed to sensory end organs. Not only do these axons fail to establish functional contacts, they also exclude appropriate axons from entering the pathways that they occupy (Brushart, 1988). However, Brushart $(1988,1993)$ demonstrated previously that, after femoral nerve transection and repair, motoneurons preferentially reinnervate the quadriceps muscle when given equal access to motor and cutaneous pathways, a process called preferential motor reinnervation (PMR). During early stages of regeneration ( 2 and 3 weeks), an equal number of motoneurons project correctly to muscle and incorrectly to skin, with many projecting collaterals to both. It is not until later stages of regeneration ( 8 and 12 weeks) that incorrect collaterals are pruned and the majority of motoneurons project their axons to muscle (Brushart, 1988, 1993). Crush proximal to the intended transection site before the axotomy and repair produced PMR within 3 weeks (Brushart et al., 1998). These findings are promising because they suggest that the generation of specificity can be accelerated in the adult. However, the need for intervention before nerve injury excludes clinical application.

The objective of this study is to determine whether electrical stimulation has the potential to become a viable clinical method for improving functional recovery after nerve transection. Previous studies have shown that electrical stimulation promotes sprouting and some early functional recovery (Nix and Kopf, 1983; Pockett and Gavin, 1985; Manivannan and Terakawa, 1994). However, the effects of electrical stimulation on regeneration after nerve transection have not been evaluated in a comprehensive manner. We have quantified motor axonal regeneration to examine (1) the rate of reinnervation of distal nerve stumps after transection injury and (2) whether it is possible to use electrical stimulation to accelerate axonal growth and rein- 
a

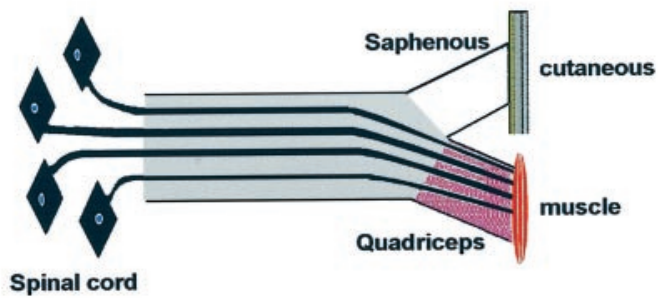

b

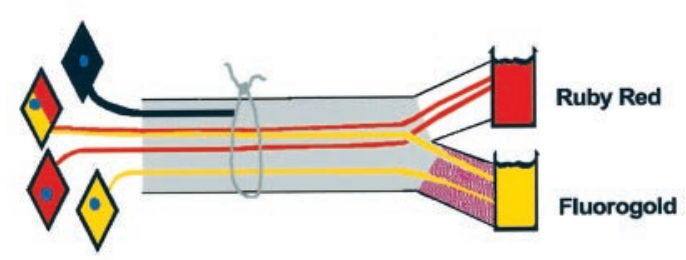

c

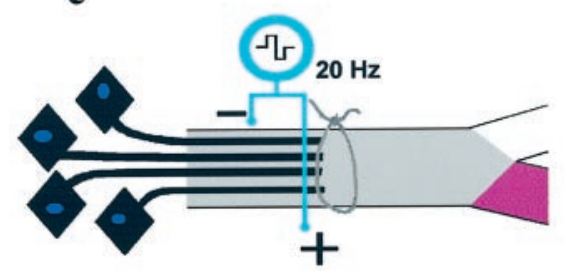

Figure 1. Diagrammatic representations of the following. $a$, The femoral nerve, the branch to the quadriceps muscles, and the saphenous nerve branch containing sensory nerves to the skin. $b$, Application of retrograde neurotracers to count motoneurons that regenerated their axons into the muscle and cutaneous branches of the cut and surgically repaired femoral nerve (see text for details). $c$, Placement of bipolar electrodes to stimulate chronically the cut and regenerating nerve fibers proximal to the site of nerve transection and surgical repair.

nervation of distal stumps, and to promote the growth of regenerating axons into appropriate pathways.

\section{MATERIALS AND METHODS}

Experimental design. Experiments were performed on the adult rat femoral nerve in which motor axons preferentially reinnervate muscle pathways (Brushart and Seiler, 1988). The femoral nerve normally contains cutaneous sensory fibers that branch to innervate the skin via the saphenous nerve. These are intermingled with sensory and motor fibers destined for the quadriceps muscle via the quadriceps muscle nerve (Fig. $1 a)$. One third of the axons derive from the $\alpha$-motoneurons that innervate the skeletal muscle fibers (Brushart and Seiler, 1987). Motor axons are found only in the muscle branch so that any motor reinnervation of the sensory branch represents a failure of specificity. Experiments were approved by a local ethical committee (Health Science Laboratory Animal Services) under the Canadian guidelines for animal experimentation.

Nerve repair. Experiments were performed under aseptic conditions on the left femoral nerves of young adult (220-240 gm) female Sprague Dawley rats anesthetized with somnotol $(30 \mathrm{mg} / \mathrm{kg}$, i.p.). The proximal femoral nerve was sharply cut, $20 \mathrm{~mm}$ proximal to the bifurcation into cutaneous and muscle nerves. The proximal and distal stumps were then carefully aligned and surgically joined within a 4-mm-long silastic nerve cuff $(0.03 \mathrm{~mm}$ inner diameter; Dow Corning) by placing a single stitch of 9-0 Ethicon (Ethicon) through the epineurium of the proximal and distal stumps under $40 \times$ magnification $(n=45$; Fig. $1 b)$. Six groups of rats were prepared; regeneration was assessed at 2, 3, 4, 6, 8, and 10 weeks after nerve transection and repair.

Electrical stimulation of axotomized and repaired motoneurons. In experiments in which transected and repaired femoral nerves were electrically stimulated, two insulated Cooner wires (A 5632) were bared of insulation for $2-3 \mathrm{~mm}$, and each was twisted to form a small loop to secure on either side of the nerve stump proximal to the suture site. The insulated wires were led to a custom-made stimulator that was encased in epoxy and covered with biocompatible silastic. The cathode was sutured alongside the femoral nerve just below its exit from the peritoneal cavity, whereas the anode was sutured to muscle close to the nerve, just proximal to the suture repair site. The wires were connected to a custom-made biocompatible implantable stimulator containing a light-sensitive diode, which turned the stimulator on and off by an external light flash (Fig. 1c). We commenced stimulation immediately after nerve repair with supramaximal pulses $(100 \mu \mathrm{sec}$; $3 \mathrm{~V})$ delivered in a continuous $20 \mathrm{~Hz}$ train by the implantable stimulator. We chose a low stimulus frequency of $20 \mathrm{~Hz}$ because it is the physiologically relevant frequency of hindlimb motoneuron discharge (Loeb et al., 1987). In the sham group of rats, the electrodes were implanted, but the stimulator was not switched on. The stimulated axotomized motoneurons and their regenerating axons were subject to short-term ( $1 \mathrm{hr}$ or $1 \mathrm{~d})$ or long-term (1 or 2 weeks) periods of continuous low-frequency electrical stimulation $(n=95)$.

Tetrodotoxin application. After determining that electrical stimulation of axotomized and repaired peripheral nerves improved regeneration, we sought to determine whether the effects of electrical stimulation could be mediated via the cell body (see Results). We first determined the blocking doses of tetrodoxin (TTX) in acute in vivo experiments (Fig. 2). Under general anesthesia (somnotol, $30 \mathrm{mg} / \mathrm{kg}$, i.p.), the femoral nerve was exposed, and a laminectomy was performed to expose and cut the parent L2 and L3 ventral roots. Ventral roots were maximally stimulated ( $2 \times$ threshold) via bipolar electrodes to evoke compound action potentials on the femoral nerve $20 \mathrm{~mm}$ from the bif urcation point to the muscle and cutaneous saphenous branches. Doses of TTX (30,60, 120, and $240 \mathrm{mg} / \mathrm{ml}$ ) were applied to the femoral nerve via a Vaseline well placed just outside the peritoneal cavity. The evoked responses on the femoral nerve distal to the TTX blockade were recorded in response to electrical stimulation of the two ventral roots at a rate of $20 \mathrm{~Hz}$. Electrical responses were recorded over a time period of $45 \mathrm{~min}$. The effective dose of TTX that blocked action potentials completely and reversibly was $60 \mathrm{mg} / \mathrm{ml}$. We then applied this dose of TTX proximal to the stimulating electrodes before the femoral nerve transection, the surgical repair, and the $1 \mathrm{hr}$ stimulation period. The electrodes and the TTX were removed before closing the wound site $(n=16)$.

Retrograde labeling of motoneurons. At the end of the regeneration period, the muscle and cutaneous branches of the left femoral nerve were isolated, cut, and backlabeled with neurotracers to identify the motoneurons innervating each branch (Fig. 1b). Fluorogold (FG; Fluorochrome Inc., Denver, CO) and fluororuby (FR; dextran tetramethylrhodamine, D-1817; Molecular Probes, Eugene, OR) were the two dyes chosen because they are effectively endocytosed and retrogradely transported (Schmued and Fallon, 1986). The muscle and cutaneous branches were cut $5 \mathrm{~mm}$ distal to the femoral bifurcation ( $25 \mathrm{~mm}$ from the repair site). In each rat, one branch was labeled with FG and the other with FR (in practice, the dye application was alternated between animals to control for possible differences in retrograde uptake and transport of the dyes). Backlabeling with FG was done by exposing the tip of the severed branch to $4 \% \mathrm{FG}$ in $0.1 \mathrm{M}$ cocodylic acid for $1 \mathrm{hr}$ in a Vaseline well, after which it was extensively irrigated and reflected to a distant portion of the wound. Backlabeling with FR was done by placing the tip of the severed branch above a small weighing paper with FR crystals for $2 \mathrm{hr}$ and then irrigating the nerve and placing it in the opposite corner of the wound to prevent cross-contamination by diffusion of tracers. Animals were kept for $72 \mathrm{hr}$ after tracer application to allow the retrograde tracers to travel back to the neuronal cell bodies.

Tissue fixation by cardiac perfusion. Rats were deeply anesthetized (somnotol, $0.12 \mathrm{ml} / 100 \mathrm{gm}$ of body weight) and perfused through the left ventricle. A warm saline flush $(100 \mathrm{ml})$ was followed by $500 \mathrm{ml}$ of ice-cold $4 \%$ paraformaldehyde in $0.1 \mathrm{M}$ phosphate buffer, $\mathrm{pH} 7.4$, over one-half hour. After perfusion, the lumbar spinal cord (T11-L1) that includes all the femoral motoneurons (Brushart and Seiler, 1987) was removed and post-fixed for $1 \mathrm{hr}$ in $4 \%$ paraformaldehyde and then cryoprotected in $30 \%$ sucrose overnight. The tissue were frozen in isopentane cooled to $-70 \mathrm{C}^{\circ}$ and stored at $-80 \mathrm{C}^{\circ}$ until further processing (Neumann et al., 1996). 
Figure 2. Diagrammatic representation of the experimental method used to establish nerve. Bipolar-stimulating electrodes placed on each of the two ventral roots that supply the motor fibers in the femoral nerve were stimulated supramaximally, and the evoked action potential was recorded on the femoral nerve distal to the application of TTX to the nerve. Doses of $60 \mathrm{mg} / \mathrm{ml}$ were found to be effective in completely blocking action potential conduction (see the text for further details). $V R$, Ventral root. the blocking dose of TTX on the femoral

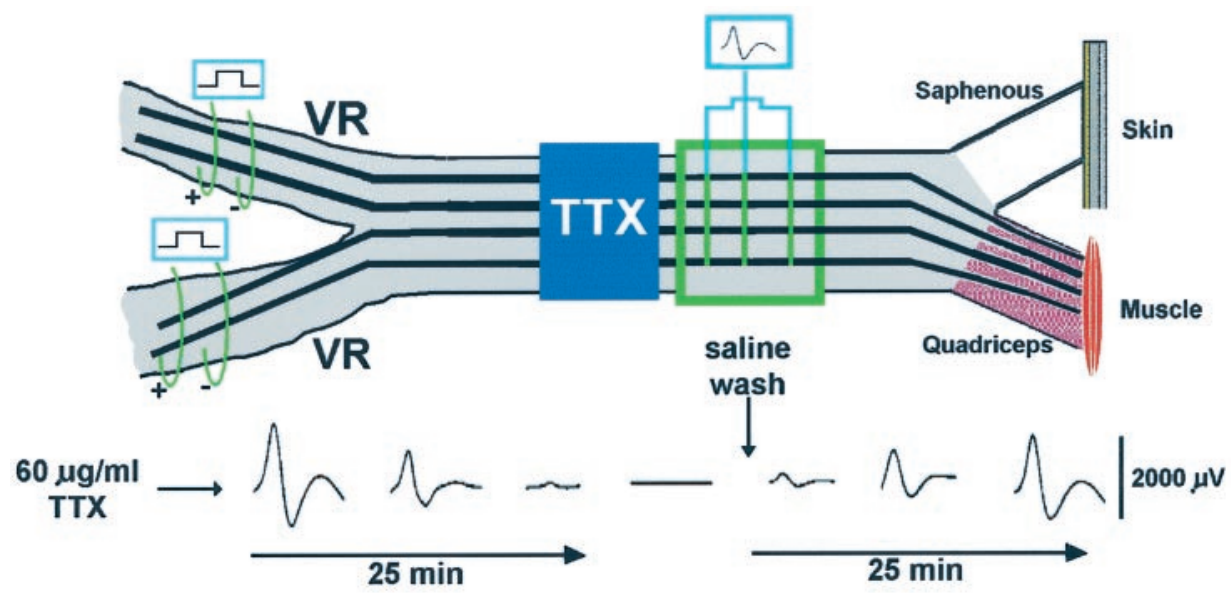

Motoneuron counting. The lumbar spinal cords were cut longitudinally at $50 \mu \mathrm{m}$ on a freezing microtome (Jung CM 3000). Sections were serially mounted on glass slides, dried, and coverslipped. Each spinal cord section was visualized at 20-40× under UV fluorescence at barrier filters of 580 $\mathrm{nm}$ for FR and $430 \mathrm{~nm}$ for FG. Motoneurons containing both FR and FG throughout the cell body were viewed by changing the fluorescent light (Fig. 3a). Backlabeled motoneurons were counted by an observer who was unaware of which branch had received FG or FR. The counting of split cells twice was corrected for by the method of Abercrombie (1946). In each group, motoneurons were scored as projecting axons (1) correctly to the muscle branch, (2) incorrectly to the cutaneous branch, or (3) simultaneously to both branches.

Statistical analysis. A one-way ANOVA was used to compare the mean number of motoneurons projecting axons to cutaneous and muscle branches within each group. A multifactorial ANOVA was used to compare the mean number of motoneurons projecting axons to cutaneous, muscle, and both branches among all groups. The same comparison was used for the stimulation, sham stimulation, and TTX groups. Statistical significance was accepted at the 0.05 level.

\section{RESULTS}

\section{Emergence of PMR associated with staggered regeneration}

At the established regeneration rate of $3 \mathrm{~mm} / \mathrm{d}$ (Gutmann et al., 1942), axons might be expected to regenerate over a distance of $25 \mathrm{~mm}$ in the course of 2 and, at most, 3 weeks. However, some regenerating femoral motor axons did not reach a point $25 \mathrm{~mm}$ from the site of surgical repair until 8 or 10 weeks later (Fig. $3 b, c$ ). Axons thus cross the repair site and/or regenerate at different speeds. This staggered progressive reinnervation was associated with progressive preferential reinnervation of appropriate muscle pathways by the regenerating motor axons. Two and 3 weeks after nerve repair, an equal number of motoneurons regenerated their axons into appropriate and inappropriate muscle and cutaneous pathways, respectively (Fig. 3b,c). In addition, a small but significant number regenerated axon collaterals into both branches, a group identified as being double labeled (Fig. 3a-c). However, between 3 and 4 weeks the number of motoneurons with correct projections to the muscle branch increased significantly, with little change in the number that regenerated their axons into the cutaneous branch. As a result, the difference between the mean number $( \pm \mathrm{SE})$ of motoneurons that regenerated their axons into muscle and cutaneous branches became statistically significant $(p<0.05)$ (Fig. 3b,c). When the backlabeling was performed at 6,8 , and 10 weeks after repair, there was a progressive increase in the number of motoneurons that regenerated specifically into the muscle branch, whereas the number in the inappropriate cutaneous branch apparently remained static (Fig. $3 b$ ). The emer- gence of PMR thus occurs between 3 and 4 weeks and becomes very distinct by 10 weeks. A small proportion of these were accounted for by a small decline in double-labeled motoneurons, the interpretation being that axonal collaterals in the "wrong" cutaneous branch are withdrawn or pruned (Brushart, 1988, 1993). Thus the emergence of PMR occurs primarily as a result of the progressive regeneration of motor axons specifically into the appropriate muscle branch between 2 and 10 weeks. The number of motoneurons that regenerated into the inappropriate cutaneous branch did not change after 2 weeks, presumably because the motoneurons that regenerated thereafter are directed specifically into the appropriate muscle branch. Eight to 10 weeks were required for all injured motoneurons to regenerate their axons into distal branches. The mean number at 10 weeks $(326 \pm 14)$ was not significantly different from the number of intact contralateral femoral motoneurons $(338 \pm 8)$.

\section{Short- and long-term electrical stimulation are equally} effective in accelerating regeneration and PMR

The effects of electrical stimulation of the transected and surgically repaired femoral nerve were dramatic. We initially chose to stimulate for a 2 week period because motor axonal regeneration into cutaneous and muscle branches is equal 2 weeks after nerve repair in this model (Brushart, 1988, 1993; Neumann et al., 1996) (Fig. $3 b$ ). We found that 2 weeks of electrical stimulation at $20 \mathrm{~Hz}$ accelerated axonal regeneration, such that all motoneurons regenerated their axons within 3 weeks, in contrast to the 8-10 weeks required without stimulation (Fig. 4).

Acceleration of axonal regeneration by electrical stimulation was accompanied by accelerated preferential growth of these regenerating axons into appropriate muscle pathways and not into inappropriate cutaneous pathways (Fig. 4a). The dramatic acceleration of both axonal regeneration and PMR by electrical stimulation is clearly seen when the total number of motoneurons that regenerated and those that regenerated into the muscle and cutaneous branches are plotted as a function of time after femoral nerve section and surgical repair (Fig. $4 b-d$ ). As shown by the open diamonds, 2 weeks of electrical stimulation promoted axonal regeneration of all injured motoneurons by 3 weeks, compared with the normal 8-10 week period required for all motoneurons to regenerate $25 \mathrm{~mm}$ from the suture site (Fig. $4 b$ ). The increase in the total number of motoneurons regenerating is accounted for by a corresponding increase in the number that regenerated axons into the appropriate motor branch (Fig. 4c). The number of motoneurons that regenerated their axons into 


\section{a}
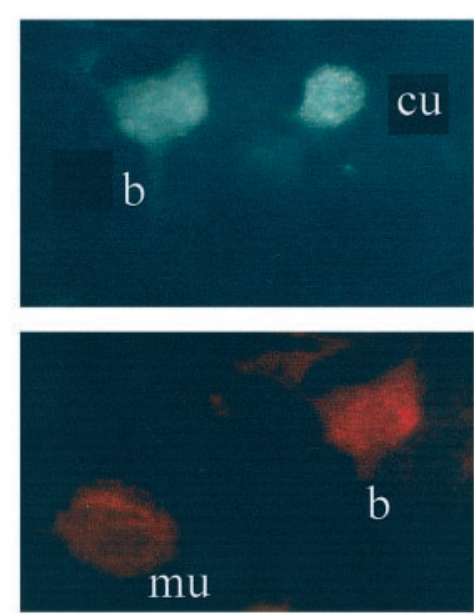

b

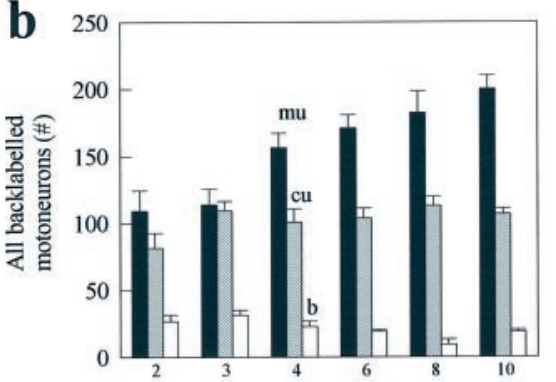

Weeks after femoral nerve repair

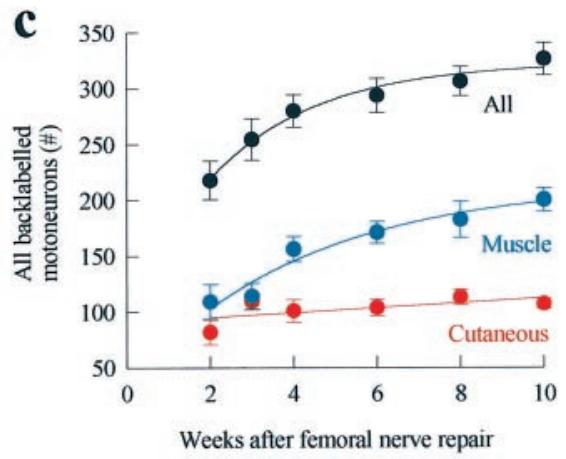

Figure 3. Counting the number of femoral motoneurons that regenerated their axons into the appropriate muscle branch and into the inappropriate cutaneous sensory branch and those that regenerated axons into both. $a$, Retrogradely labeled motoneurons that had regenerated their axons into the appropriate muscle branch ( $\mathrm{mu}$; fluororuby) or the inappropriate cutaneous sensory branch ( $c u$; fluorogold) and those that regenerated axons into both ( $b$; double labeled). $b$, The mean number of backlabeled motoneurons that regenerated into the appropriate muscle branch ( $\mathrm{mu}$; filled bars), the inappropriate cutaneous branch ( $\mathrm{cu}$; stripped bars), and both branches (b; open bars) 2, 3, 4, 6, 8, and 10 weeks after femoral repair. $c$, The mean number \pm SE of total backlabeled motoneurons $(A l l)$ that regenerated their axons into the appropriate muscle branch (Muscle) and into the inappropriate cutaneous branch (Cutaneous) as a function of time after femoral nerve transection and repair.

the sensory branch did not increase significantly between 2 and 10 weeks. Noticeably, however, the variability in this number decreased substantially as a function of time (Fig. 4d). Although there was also a trend for the number of double-labeled motoneurons to decline with stimulation, the numbers were not statistically different $(p>0.05)$.
To optimize the potential use of electrical stimulation for clinical nerve repair, we progressively reduced the duration of low-frequency continuous electrical stimulation from 2 weeks to $1 \mathrm{hr}$. Whether the proximal nerve stump was electrically stimulated at $20 \mathrm{~Hz}$ for a 2 week period or for as little as $1 \mathrm{hr}$ (Fig. 4), the stimulation accelerated axonal regeneration so that all axotomized motoneurons regenerated by 3 weeks (Fig. $4 b$ ). This is well illustrated by comparing the effectiveness of short- and long-term electrical stimulation with the effects of sham stimulation on the number of motoneurons that were backlabeled from the muscle and cutaneous sensory nerve branches 3 weeks after cutting and repairing the femoral nerve (Fig. 5). We made the comparison at 3 weeks after nerve repair, at a time when the number of motoneurons that have regenerated is still $\sim 50 \%$ of the total and PMR has not emerged in sham-stimulated femoral nerves. The histograms in Figure 5 demonstrate that short- and long-term stimulation were equally effective in increasing the number of motoneurons that regenerated their axons into the muscle branch without affecting the number that regenerated into the inappropriate cutaneous branch.

The dramatic effect of electrical stimulation in accelerating regeneration and PMR is consistent from animal to animal (Fig. $5 b, c)$. The contrast between the number of motoneurons that regenerated axons in the distal nerve branches after $1 \mathrm{hr}$ of stimulation compared with sham stimulation demonstrates (1) incomplete axonal regeneration and lack of preferential motor reinnervation, 3 weeks after femoral nerve transection and repair without stimulation, and (2) the effectiveness of electrical stimulation in increasing the number of motoneurons that regenerated their axons over a $25 \mathrm{~mm}$ distance. The consistency between individual animals is particularly striking in the context of the inherent variability of surgical procedures (Fig. $5 b, c$ ). Our data thus demonstrate that we can reduce the duration of continuous low-frequency stimulation and still accelerate motor axonal regeneration in the appropriate muscle pathways to result in preferential motor reinnervation.

\section{The positive effect of short-term electrical stimulation is mediated via the cell body}

The effectiveness of only $1 \mathrm{hr}$ of stimulation of the axotomized motoneurons suggested that the site of action of the electrical stimulation could be the cell body, possibly by initiating the growth program earlier. To test this hypothesis, we blocked the retrograde transmission of action potentials to the cell body as well as the afferent-evoked anterograde excitation of the motoneurons using a TTX block of sodium channels. We found that the TTX blockade completely prevented the effect of the $1 \mathrm{hr}$ stimulation (Fig. 6). These experiments localize the site of action of the electrical stimulation to the cell body.

\section{DISCUSSION}

In this study, we used an adult rat peripheral nerve transection and surgical repair model to demonstrate that axons continue to reinnervate the distal pathway for protracted periods of up to 10 weeks. At a regeneration rate of $3 \mathrm{~mm} / \mathrm{d}$, many axons that would be expected to regenerate over a distance of $25 \mathrm{~mm}$ in 2-3 weeks did not do so until 8-10 weeks had elapsed. This process of gradual or staggered reinnervation is associated with progressive reinnervation of appropriate muscle pathways by regenerating motor axons (PMR). We have also demonstrated that both the staggered axonal regeneration and PMR can be accelerated by electrical stimulation of the axotomized motoneuron. This posi- 
Figure 4. Effects of electrical stimulation on motor axonal regeneration and PMR. $a$, The mean number $\pm \mathrm{SE}$ of motoneurons that regenerated into appropriate muscle (mu; filled bars) and inappropriate cutaneous (cu; stripped bars) branches and both branches $(b$; open bars) 2,3 , and 8 weeks after femoral nerve transection and surgical repair and 2 weeks of 20 $\mathrm{Hz}$ continuous electrical stimulation. $b-d$, Comparison of the mean number $\pm \mathrm{SE}$ of motoneurons that regenerated after femoral nerve transection and surgical repair without $(\bullet)$ and with $20 \mathrm{~Hz}$ continuous electrical stimulation for $1 \mathrm{hr}(\nabla), 1 \mathrm{~d}(\square), 1$ week $(\triangle)$, and 2 weeks $(\diamond)$. $b$, All motoneurons. $c$, Motoneurons that regenerated into the appropriate muscle branch. $d$, Motoneurons that regenerated into the inappropriate cutaneous branch. The shaded horizontal bar in $b-d$ represents $\pm \mathrm{SE}$ of the mean number of regenerated motoneurons 8 and 10 weeks after femoral nerve repair with no stimulation, when there was no longer any significant difference between mean number of regenerated motoneurons $(p>0.05)$. stim, Stimulation.
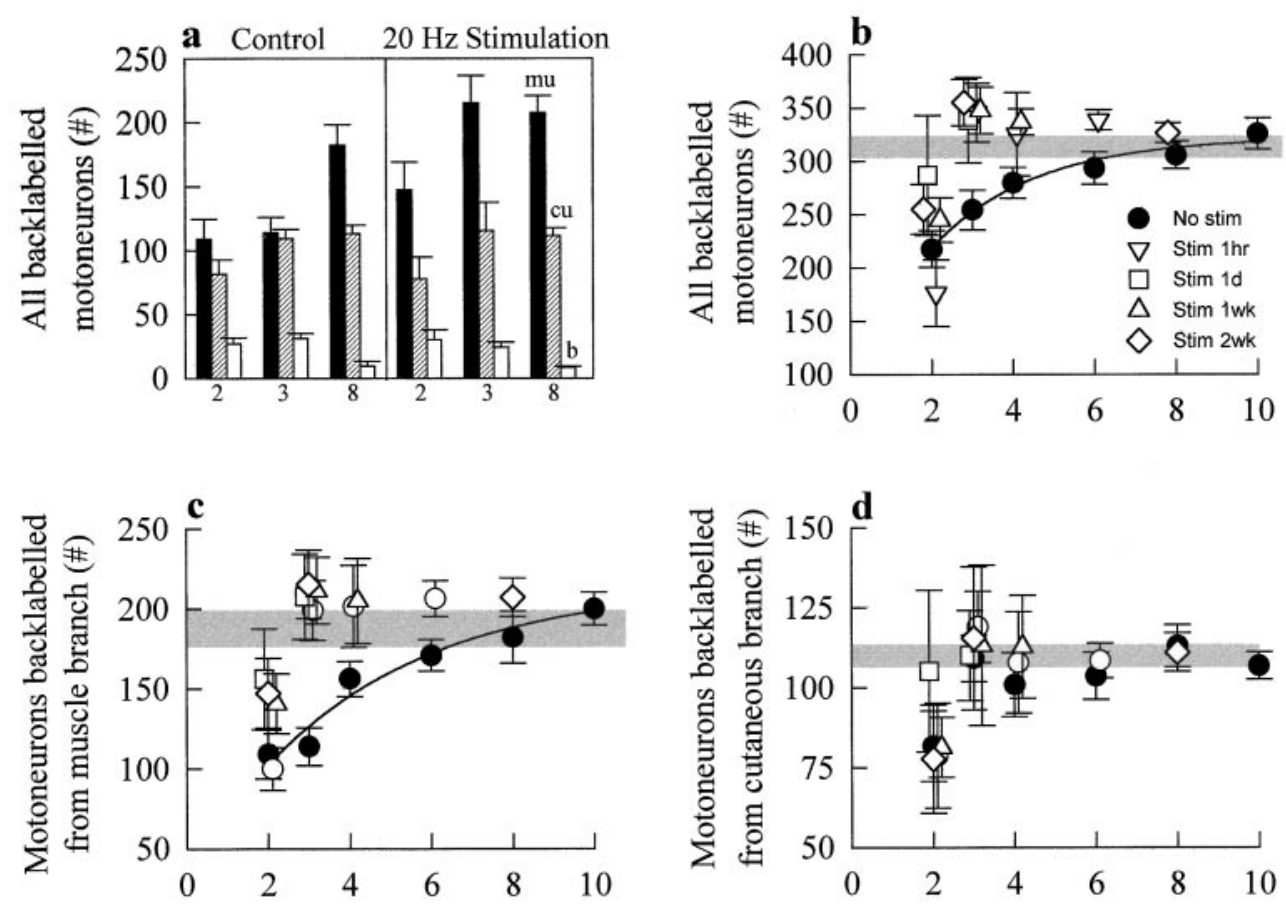

Weeks after femoral nerve repair

Weeks after femoral nerve repair tive effect of electrical stimulation is mediated at the cell body and requires as little as $1 \mathrm{hr}$ of electrical activity.

\section{Staggered axonal regeneration}

When the femoral nerve was cut and surgically reunited, the number of motoneurons that regenerated their axons over a $25 \mathrm{~mm}$ distance increased to a maximum by $8-10$ weeks after repair (Fig. 3). Because this number equaled the total number of motoneurons that supplied the intact femoral nerve in the contralateral leg, it is evident that all motoneurons eventually regenerated their axons across the suture line. However, this process occurred gradually over a 10 week period. The speed of axonal regeneration has classically been determined by measuring the distance from the injury site at which a pinch stimulus evokes a response (Young and Medawar, 1940). The widely reported rate of regeneration of $3 \mathrm{~mm} / \mathrm{d}$ (Gutmann et al., 1942; Seddon et al., 1943; Sunderland, 1947; for review, see Sunderland, 1978) thus describes only the outgrowth of the fastest-growing sensory axons. The prolonged period over which axons regenerate across a surgical repair would thus evade detection. Although this prolonged period has long been suspected on the basis of clinical experience (Sunderland, 1978; Kline and Hudson, 1995), this is the first experimental quantification of the prolonged duration of axonal regeneration after a surgical cut and repair. A distance of $25 \mathrm{~mm}$ is traversed by waves of regenerating motor axons that arrive at the point of backlabeling at widely different times. Interestingly, this finding is quite consistent with and provides a clear explanation for "unpublished findings of an unusually broad peak of axonally transported radioactivity in regenerating nerves after transection injuries" that were reported in the paper of Forman and Berenberg (1978).

Because the fastest axons regenerate at a rate of $1-3 \mathrm{~mm} / \mathrm{d}$, delays of days and weeks must occur before many axons enter the distal nerve stumps or as they propagate within it. The former possibility was suggested by the drawings of Ramon y Cajal
(1928) of the tortuous pathways taken by growth cones crossing from proximal to distal nerve stumps. Characteristically, axonal sprouts emerge from the first node of Ranvier proximal to an injury with many axon collaterals (5-20) entering the distal nerve stump (Morris et al., 1972; Mackinnon et al., 1991). Nonetheless, sprouts may bud from even more proximal nodes (Mackinnon et al., 1991) that could have the effect of staggering regeneration. In addition, it is possible that the outgrowth of many daughter axon collaterals from the parent axon slows axonal regeneration. Perhaps axons with multiple sprouts grow slowly until enough sprouts are pruned to allow routing of most structural materials to the dominant sprout that, thereafter, regenerates more rapidly. It is conceivable that axon collaterals from a motoneuron regenerated into both muscle and cutaneous nerve branches but that, at the time of backlabeling at 2 weeks and a distance of $25 \mathrm{~mm}$ from the site of entry of the regenerating axons into muscle or cutaneous pathways, most of the inappropriate collaterals were removed or pruned so rapidly that they were not detected in the wrong pathways as double-labeled motoneurons or as motoneurons with axons in the sensory branch.

\section{Electrical stimulation and accelerated axonal regeneration}

Electrical stimulation dramatically accelerated axonal regeneration. Electrical stimulation, applied immediately after surgical repair of the cut femoral nerve, promoted the regeneration of all motor axons over a $25 \mathrm{~mm}$ distance from the surgical site in 3 weeks. The regenerating axons required $8-10$ weeks to reach this level without stimulation (Fig. $3 b, c$ ). This finding substantiates the conclusions that electrical stimulation can accelerate axonal regeneration that were drawn from experiments that detected slightly earlier and larger electromyographic signals and accelerated recovery of force in reinnervated rabbit soleus muscles after crush injury (Nix and Kopf, 1983). The acceleration of axonal regeneration is much more dramatic in our study, probably 
a
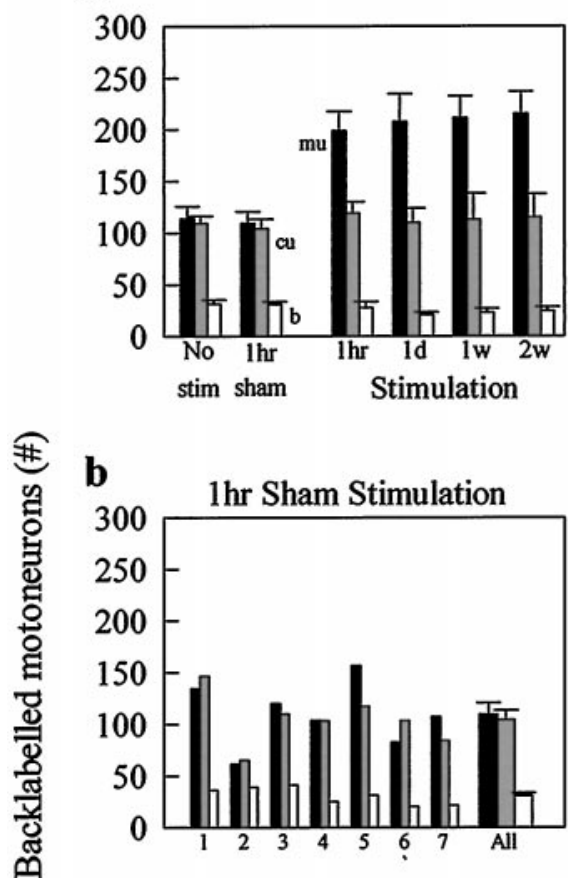

c $1 \mathrm{hr} 20 \mathrm{~Hz}$ Continuous Stimulation

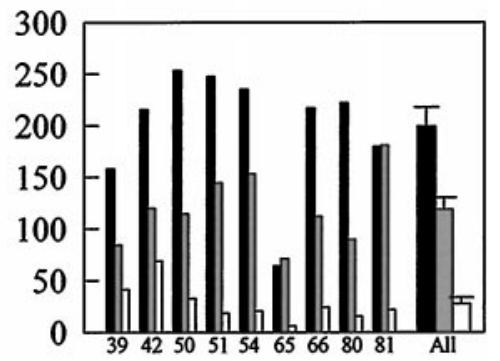

Figure 5. Short-term stimulation is as effective as long-term stimulation in accelerating axonal regeneration and PMR. $a$, Comparison of the effects of different periods of $20 \mathrm{~Hz}$ continuous electrical stimulation ( $1 \mathrm{hr}, 1 \mathrm{~d}, 1$ week, and 2 weeks) on the mean number \pm SE of motoneurons that regenerated into muscle ( $m u$; filled bars), cutaneous ( $\mathrm{cu}$; stripped bars), and both ( $b$; open bars) branches of the femoral nerve 3 weeks after nerve repair with the effects of no stimulation or sham stimulation. $b, c$, Data from individual rats (numbered on the $x$-axis) showing the effects of $1 \mathrm{hr}$ of sham stimulation $(b)$ and $1 \mathrm{hr}$ of $20 \mathrm{~Hz}$ continuous electrical stimulation of the proximal nerve stump immediately after nerve repair (c). stim, Stimulation.

because (1) the nerve section injury prolonged the period of axonal outgrowth from the proximal nerve stump more than did the crush injury and (2) there are substantial delays associated with the reformation of nerve-muscle connections that are avoided by determining the number of motoneurons that regenerated into the distal nerve stump.

\section{Preferential motor reinnervation}

Findings that femoral motor axons regenerated equally into the appropriate muscle and cutaneous branches of the nerve 2-3 weeks after nerve repair are quite consistent with previous findings of Brushart $(1988,1993)$. With continued regeneration, preferential reinnervation of the muscle nerve (PMR) was demonstrated at 8 and 12 weeks. Our present study evaluated this process at more frequent intervals $(2,3,4,6,8$, and 10 weeks).

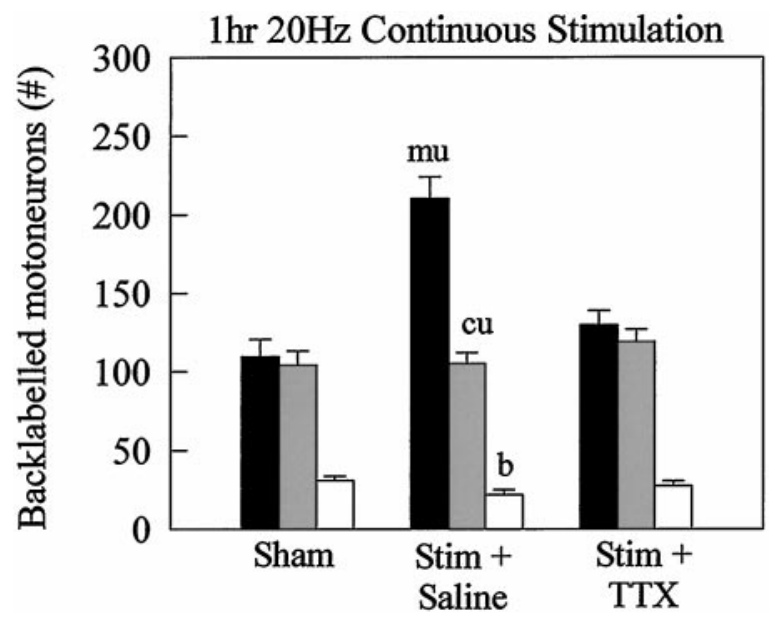

Figure 6. TTX block of retrograde transmission of action potentials to the cell body. TTX $(60 \mathrm{mg} / \mathrm{ml})$ completely blocked the effect of $1 \mathrm{hr}$ of $20 \mathrm{~Hz}$ continuous electrical stimulation in accelerating regeneration and PMR 3 weeks after nerve transection and surgical repair. $b$ (open bars), Both branches; $\mathrm{cu}$ (stripped bars), cutaneous branch; mu (filled bars), muscle branch; Stim, stimulation.

The progressive increase in correct projections from week 4 to week 10 paralleled a large increase in the total number of motoneurons regenerating (Fig. 3b,c). Hence PMR emerges with time concurrent with a progressive increase in the number of motoneurons that regenerate their axons into the distal nerve stumps. Differences between the number of motoneurons that regenerated into the muscle compared with that into the cutaneous nerve branches became more prominent as the number of motoneurons that participated in the regeneration increased. It was particularly striking that the emergence of the PMR was directly associated with the increased numbers of motoneurons that regenerated axons specifically into the muscle nerve as opposed to the cutaneous nerve. In fact, the mean number of motoneurons mean (120) that had regenerated their axons inappropriately into the cutaneous nerve branch remained unchanged from 2 weeks onward. This finding suggests that a mechanism capable of directing highly specific regeneration becomes activated 3 weeks after repair. The presence of the L2/HNK-1 carbohydrate in muscle but not in cutaneous pathways and its selective upregulation by regenerating motor axons suggest that it may participate in this process (Martini et al., 1994). Although there was a small decline in the number of motoneurons that regenerated into both muscle and cutaneous branches with time, the "pruning" is a relatively minor contributor to the emergence of PMR in adult rat nerve regeneration compared with juvenile (cf. Brushart, 1990, 1993).

\section{Electrical activity accelerates PMR}

Electrical stimulation accelerated both axonal regeneration and the development of PMR. The difference between the number of motoneurons projecting to muscle and that to cutaneous branches of the femoral nerve normally seen 8 weeks after nerve repair was present after only 3 weeks (Fig. $4 a$ ). This dramatic effect of electrical stimulation mimicked the effects of a proximal crush in accelerating PMR (Brushart et al., 1998). Interestingly, under both conditions, the PMR was associated with increased numbers of motoneurons that regenerated their axons into the distal nerve stump [compare the present study, Fig. $4 a$, with Brushart et al. (1998), their Fig. 2]. 


\section{Electrical stimulation accelerates axonal regeneration and PMR via the cell body}

Tetrodotoxin blockade of action potentials to the cell body abolished the effects of electrical stimulation on the speed and the specificity of motor axonal regeneration. This suggests that electrical stimulation produces its effects at the level of the cell body. These findings are consistent with in vitro evidence of depolarization-induced calcium entry into the cell body that is associated directly with upregulation of immediate early genes, initiation of gene expression, and neurite outgrowth (Kocsis et al., 1994). One possibility is that electrical stimulation may mediate its positive effect on regeneration by enhancing the cell body response that, in turn, is partially attributed to an enhanced production of the neurotrophin brain-derived neurotrophic factor (BDNF) and its high affinity receptor TrkB. BDNF and TrkB mRNA and protein levels are elevated after axotomy of motoneurons (Meyer et al., 1992; Funakoshi et al., 1993; Piehl et al., 1994; Kobayashi et al., 1996; Fu and Gordon, 1997). BDNF has also been shown to promote phenotypic maintenance after motoneuron axotomy (Yan et al., 1994). Moreover, the expression of BDNF and TrkB has been shown to be regulated by neuronal activity (Zafra et al., 1990, 1991; Tao et al., 1998) and physiological stimuli (Castren et al., 1992).

\section{Significance}

One hour of electrical stimulation dramatically accelerates both axonal regeneration and PMR in the adult rat femoral nerve transection and repair model. Both of these effects have the potential for clinical application. Acceleration of regeneration would counteract the delay in reinnervation of pathways and end organs that compromises functional outcome (see Fu and Gordon, 1995a,b, 1997). Augmentation of PMR could improve recovery after injuries to nerve trunks containing both cutaneous and muscle axons. One hour of stimulation can easily be applied during peripheral nerve surgery. The promising and potential usef ulness of the technique clearly warrants further investigation.

\section{REFERENCES}

Abercrombie M (1946) Estimation of nuclear population from microtome sections. Anat Rec 94:239-247.

Brushart TM (1988) Preferential reinnervation of motor nerves by regenerating motor axons. J Neurosci 8:1026-1031.

Brushart TM (1990) Preferential motor reinnervation: a sequential double-labeling study. Restor Neurol Neurosci 1:281-287.

Brushart TM (1993) Motor axons preferentially reinnervate motor pathways. J Neurosci 13:2730-2738.

Brushart TM, Seiler WA (1987) Selective reinnervation of distal motor stumps by peripheral motor axons. Exp Neurol 97:290-300.

Brushart TM, Gerber J, Kessens P, Chen Y-G, Royall RM (1998) Contributions of pathway and neuron to preferential motor reinnervation. J Neurosci 18:8674-8681.

Castren E, Zafra F, Theonen H, Lindholm D (1992) Light regulates expression of brain-derived neurotrophic factor mRNA in rat visual cortex. Proc Natl Acad Sci USA 89:9444-9448.

Forman DS, Berenberg RA (1978) Regeneration of motor axons in the rat sciatic nerve studied by labeling with axonally transported radioactive proteins. Brain Res 156:213-225.

Fu SY, Gordon T (1995a) Contributing factors to poor functional recovery after delayed nerve repair: prolonged axotomy. J Neurosci 15:3876-3885.

Fu SY, Gordon T (1995b) Contributing factors to poor functional recovery after delayed nerve repair: prolonged denervation. J Neurosci 15:3886-3895.

Fu SY, Gordon T (1997) The cellular and molecular basis of peripheral nerve regeneration. Mol Neurobiol 14:67-116.

Funakoshi H, Frisen J, Barbany G, Timmusk T, Zachrisson O, Verge V,
Persson H (1993) Differential expression of mRNA for neurotrophins and their receptors after axotomy of the sciatic nerve. J Cell Biol 123:455-465.

Guttmann E, Guttmann L, Medawar PB, Young JZ (1942) The rate of regeneration of nerve. J Exp Biol 19:14-44.

Kline DG, Hudson AR (1995) Nerve injuries: operative results for entrapments and tumors. Philadelphia: Saunders.

Kobayashi NR, Bedard AM, Hinchke MT, Tetzlaff W (1996) Increased expression of BDNF and TrkB mRNA in rat facial motoneurons after axotomy. Eur J Neurosci 8:1018-1029.

Kocsis JD, Rand MN, Lankford KL, Waxman SC (1994) Intracellular calcium mobilization and neurite outgrowth in mammalian neurons. J Neurobiol. 25:252-264.

Langley JN, Hashimoto M (1917) On the suture of separate nerve bundles in a nerve trunk and on internal nerve plexuses. J Physiol (Lond) 51:318-345.

Loeb GE, Marks WB, Hoffer JA (1987) Cat hindlimb motoneurons during locomotion. IV. Participation in cutaneous reflexes. J Neurophysiol 57:563-573.

Mackinnon S, Dellon L, O’Brien J (1991) Changes in nerve fibre numbers distal to nerve repair in the rat sciatic nerve model. Muscle Nerve 14:1116-1122.

Manivannan S, Terakawa S (1994) Rapid sprouting of filopodia in nerve terminals of chromaffin cells, PC12 cells, and dorsal root neurons induced by electrical stimulation. J Neurosci 14:5917-5928.

Martini R, Schachner M, Brushart TM (1994) The L2/HNK-1 carbohydrate is preferentially expressed by previously motor axonassociated Schwann cells in reinnervated peripheral nerves. J Neurosci 14:7180-7191.

Meyer M, Matsuoka I, Wetmore C, Olsen L, Thoenen H (1992) Enhanced synthesis of brain derived neurotrophic factor in the lesioned peripheral nerve: different mechanisms are responsible for the regulation of BDNF and NGF mRNA. J Cell Biol 119:45-54.

Morris JH, Hudson AR, Weddell GA (1972) Study of degeneration and regeneration in the divided rat sciatic nerve based on electron microscopy. II. The development of the "regenerating unit." Z Zellforsch Mikrosk Anat 124:103-130.

Neumann CM, Brushart TM, Gordon T (1996) Increasing specificity of regenerating motor nerves. Soc Neurosci Abstr 22:1487.

Nix WA, Kopf HC (1983) Electrical stimulation of regenerating nerve and its effect on motor recovery. Brain Res 272:21-25.

Piehl F, Frisen J, Risling M, Hokfelet T, Cullheim S (1994) Increased trkB mRNA expression by axotomized motoneutons. NeuroReport 5:697-700.

Pockett S, Gavin RM (1985) Acceleration of peripheral nerve regeneration after crush injury in the rat. Neurosci Lett 59:221-224.

Ramon y Cajal S (1928) Degeneration and regeneration of the nervous system. London: Oxford UP.

Schmued LC, Fallon JH (1986) Fluoro-gold: a new fluorescent retrograde axonal tracer with numerous unique properties. Brain Res 377:147-154.

Seddon JJ, Medawar PB, Smith H (1943) Rate of regeneration of peripheral nerves in man. J Physiol (Lond) 102:191-215.

Sunderland S (1947) Rate of regeneration in human peripheral nerves. Arch Neurol Psychiatr 58:251.

Sunderland S (1978) Nerve and nerve injuries. London: Churchill Livingstone.

Tao XU, Finkbiner S, Arnold DB, Shaywitz AJ, Greenberg ME (1998) Calcium influx regulates BDNF transcription by a CREB family transcription factor-dependent mechanism. Neuron 20:709-726.

Yan Q, Matheson C, Lopez OT, Miller JA (1994) The biological responses of axotomized adult motoneurons to BDNF. J Neurosci 14:5281-5291.

Young JZ, Medawar PB (1940) Fibre suture of peripheral nerves. Measurement of the rate of regeneration. Lancet ii:126-128.

Zafra F, Hengener B, Leibrock J, Thoenen H, Lindholm D (1990) Activity dependent regulation of BDNF and NGF mRNAs in the rat hippocampus is mediated by non-NMDA glutamate receptors. EMBO J 9:3545-3550.

Zafra F, Castren E, Theonen H, Lindhol D (1991) Interplay between glutamate and GABA transmitter systems in the physiological regulation of BDNF and NGF synthesis in hippocampal neurons. Proc Natl Acad Sci USA 88:10037-10041. 